\title{
HEAT STORAGE SYSTEM WITH PHASE CHANGE MATERIALS IN COGENERATION UNITS: STUDY OF PRELIMINARY MODEL
}

\author{
Claudio Caprara, Giovanni Stoppiello
}

\section{Introduction}

Farm activity is always marked by a numerous and extremely varied series of operations, most of them are climate changes depending and seasonally carried out. According to the type of the farm and its mechanization level, corresponding energy demand is therefore very different in time, both in daytime and during the year. Hourly load curves often show several peaks during the day corresponding to the key moments of the working cycle, which have to be fulfilled together with usual and domestic energy uses. Besides, daily energy demand is depending on the season and on the production step of the moment. Heat and electrical power demands rarely coincide in time, for they often correspond with operations totally disconnected each other.

For all these reasons energy management in farms is quite complicated and many efforts have to be carried out in order to achieve economic and environmental sustainability.

For energy saving, it might be necessary to level off energy demand during the day and to use renewable sources of energy. Cogeneration systems could be very helpful to reduce fuel consumption, as well. Nevertheless, these units are still not very suitable to be integrated in energy supply systems for farms because of their little flexibility and possibility to rapidly follow load changes, both for heat and for power.

In order to approach daily energy demand peaks and to disconnect heat and power production from their different utilisation times, heat storage units are nowadays wider and wider spreading afterwards cogeneration systems.

In this work, a numerical simulation model for a thermal energy storage (TES) unit is presented. This unit integrates a cogeneration plant made up of a re-

Paper received 21.01.2008; accepted 05.06.2008

Dr. Claudio Caprara, Researcher, Ing. Giovanni Stoppiello, $\mathrm{PhD}$ student, Agricultural Economics and Engineering Dept., University of Bologna, Via G.Fanin 50, 40127 Bologna, Italy, e-mail of corresponding author: claudio.caprara@unibo.it ciprocating engine and it is based on Phase Change Materials (PCMs) behaviour. These ones seem to be the best solution in heat storage, especially for their high energy density (properly due to phase changes) by which large spaces and high heat losses are avoided. Besides, unlike sensible heat exchange, latent heat one permits to achieve thermal transfers at constant working temperatures, thus improving, in some cases, system efficiency and energy supply management.

PCMs are usually used in domestic and little size cogeneration units. Still less applications in more complex and bigger systems are present. For this reason, even studies and publications about their use in farms energy supply systems are very few $[1,2,3]$.

The main technical constraints preventing large use of PCMs are represented by their too low thermal conductivity, that is responsible for unacceptably long times of thermal exchange, their chemical aggressiveness (only for inorganic salts), and their loose of efficiency in time, especially due to supercooling and phase segregation [4].

The present simulation model is concerning a latent heat storage unit that minimizes these undesired aspects by adopting the materials encapsulation technique. Therefore, the model can be seen as an useful tool for plant design, as well.

On the other hand, the main goal of this work was developing an extremely versatile computational software tool by which a lot of different working conditions can be simulated, so that adapt its results to as many real cases as possible.

For this purpose, it was necessary to develop a simplified process algorithm by which results can be only considered as theoretical background for deeper technical and economical analysis, regarding specific real applications.

\section{Materials and Methods}

\subsection{System description}

\subsubsection{Reciprocating engine}

As energy cogeneration unit a reciprocating engine is intended to be used. It was tought to be a diesel en- 
gines with a fixed air excess of $20 \%$. Its electrical efficiency is fixed to 0,4 for each load value while heat recovery is obtained only from exhausts thermal content, with a net efficiency of $30 \%$ (in respect with heating value of the fuel) [5]. The only use of exhausts allows to work with PCMs which have higher phase change temperatures, so that an higher temperature difference $\Delta \mathrm{T}$ with heat transfer fluid is established. As a consequence an acceptably rapid heat exchange is achieved even with low thermal conductivity values of materials. Exhausts flow per kWe and their outlet temperature from the engine are calculated according to the elementary composition of fuel and air excess.

\subsubsection{Heat storage unit}

Heat storage unit is made up of a cylindrical tank in which a fixed bed of spherical capsules is set up. Inside the tank there is also a pipe coil that is totally plunged in the bed so that it is in deep contact with the spheres (fig. 1). Both spheres and coil are copper made. The capsules are filled up with phase change materials, the amount of which is enough to fill the whole inner volume of the spheres, when they are totally in liquid phase (less density). These materials are responsible for heat storage and release through their alternating cycles of solidification and liquefaction: in heat storage phase, such as during the hours when thermal energy content of the exhausts is higher than energy demand, surplus heat is transferred from exhausts to PCMs through the spherical shell thickness. In this way, they change from solid to liquid phase according to their melting latent heat (stored heat).

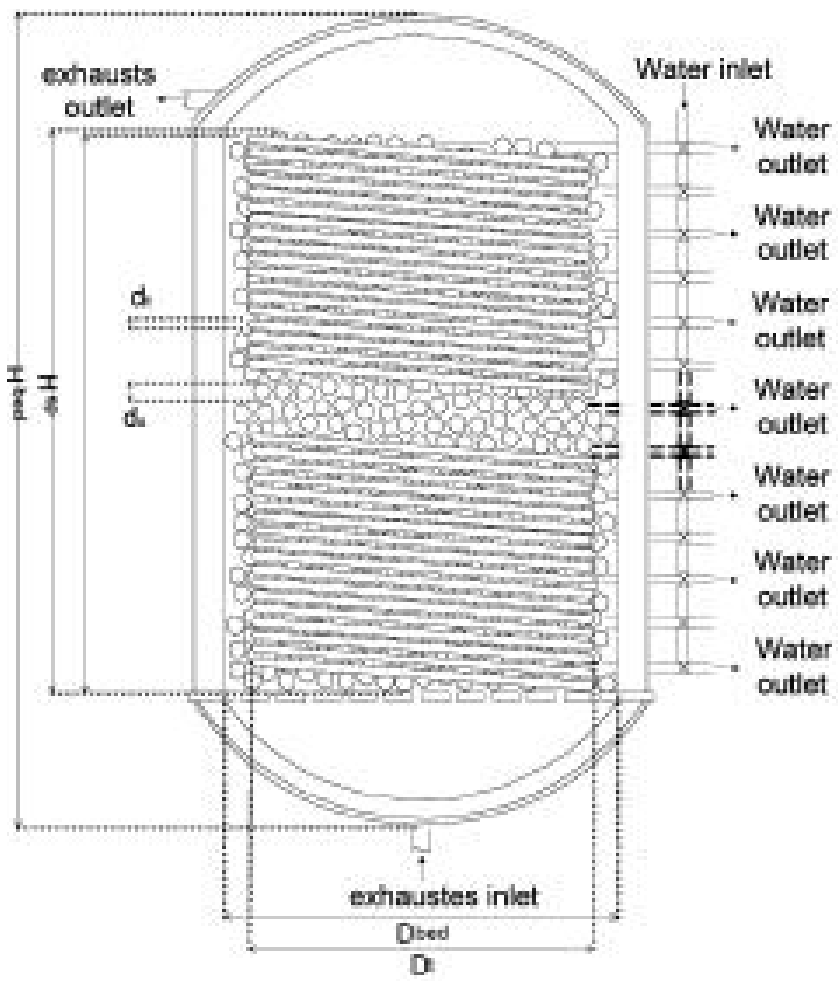

Fig. 1 - Heat storage unit.
When energy demand is higher than exhausts heat content, remaining required heat is supplied by the PCMs which harden, releasing solidification heat to the fluid inside the coil. Thermal energy is therefore transferred to heat transfer fluid both from the exhausts and from the spheres through convective and conductive heat exchanges which are controlled and regulated by means of the particular shape of the coil: it is made of several identical segments, each of them has its own inlet tube and it is connected to the others by flux exchange valves.

By switching these valves in different positions, it is possible to choose how many segments of the coil have to be used for the fluid flow, in order to change available heat transfer surface. Besides, it is possible to change fluid flow rate through the coil, too. In this way, it is possible to transfer heat to the fluid following the hourly energy demand of the farm. PCMs encapsulation technique is especially used to improve heat exchange between materials and exhausts, since an high conductivity solid material (copper) is set between them and their contact surface is augmented. Exhausts are blown into the tank from the bottom of the bed through a grid that supports the spheres,

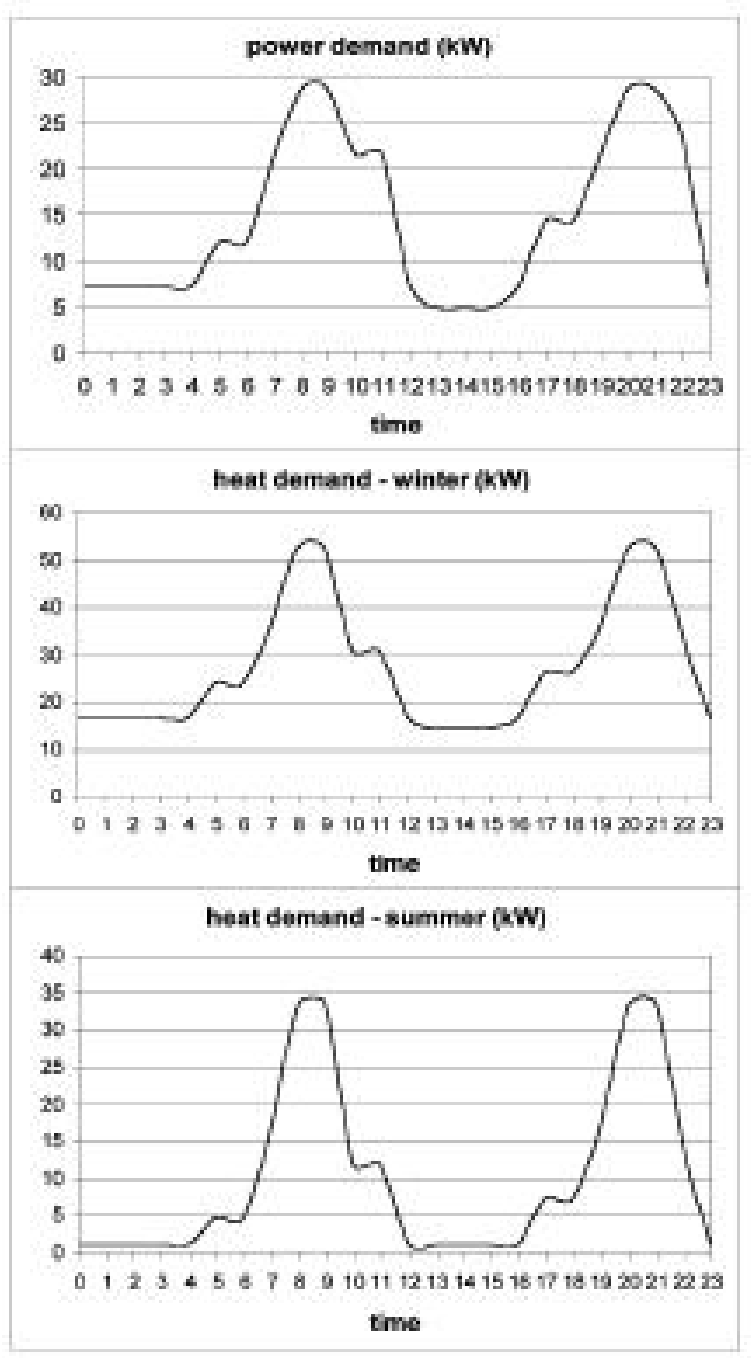

Fig. 2 - Energy load curves for cattle farm. 
thus they are obliged to pass throughout the voids of the bed, licking the whole external surface of the capsules.

In this way, heat exchange turns out enough to have acceptable working times in spite of the low thermal conductivity of most the PCMs Besides, encapsulation technique reduces environmental hazards due to chemical attack by the PCMs (especially inorganic salts) towards tank walls and it is also very suitable to face volume changes [2].

\subsubsection{Case study}

In order to apply the model to a real case, energy load curves of a cattle farm were taken in exam (100 cattle heads) [6] and seasonally climate changes of Bologna were considered ${ }^{1}$.

Energy load curves are hourly developed and they include both domestic and production demands (Fig. 2 ). In this case, two main daily peaks are noticeable, corresponding to milking phases. Besides, load curves refer to two different working conditions, such as winter and summer ones. Power consumptions are the same in both the seasonally conditions, while heat consumptions differ for room heating and food processing during the two mentioned periods $[6,7]$.

\subsection{Model development}

Present study deals with thermodynamic behaviour of thermal energy storage unit related to power generation and energy demands variability. It is carried out by data acquisition and elaboration software LabView 8.0.

The model gives as results the hourly changes of the following system characteristics:

- Hourly power and heat demands of considered farm

- Heat and power cogeneration by the engine

- Thermal energy balance and heat loss

- Heat transfer fluid flow

- Pipe coil required length

- Absolute and percentage amounts of PCMs in liquid and solid phases

As input data, the model requires:

- Power of cogenerator

- Tank dimensions

- Spheres dimensions

- Diameter and thickness of pipe coil

- Thermo-physics of PCMs, such as

$\dagger$ Liquid and solid density

$\dagger$ Thermal conductivity

$\dagger$ Melting and solidification latent heat

$\dagger$ Melting temperature

Main characteristics of some PCMs are shown in Table 1 [8].

All these required parameters are directly chosen

1 External temperature data have been furnished by ARPA, Emilia Romagna. and inserted into the model by the operator, as to have as much flexibility as possible in operational conditions.

According to the scope of the study and in order to simplify the software algorithm, several hypothesis were made, some of which are verified by the same simulator itself:

- Use of pure substances as phase change materials (single value for melting temperature).

- Use of only latent heat for heat exchange (stationary regime, initial temperature of the spheres equal to melting temperatures of materials).

- Total heat supply from the exhausts towards the PCMs (exhausts outlet temperature from the tank only just higher than spheres temperature, $\left(\mathrm{T}_{e \mathrm{x}}=\mathrm{T}_{s}\right.$ $+5^{\circ} \mathrm{C}$ ).

- Only conductive heat exchange between spheres surface and PCMs is considered.

- Heat transfer fluid always in liquid phase.

- Equal phases percentages of solid and liquid PCMs $(50 \%)$ as initial composition.

From a theoretical point of view, the model is only based on thermal energy balance equations and stationary heat exchange relations. For the considered materials, they can be generally written as follows:

$$
\begin{aligned}
& Q=m^{\prime} \cdot c_{2} \cdot \Delta T+m \cdot \lambda \\
& Q=m^{\prime} \cdot c_{,} \cdot \Delta T+m^{\prime} \cdot \lambda \\
& Q=K \cdot A \cdot \Delta T_{m} .
\end{aligned}
$$

By using these equations for all fluids and solids taking part in heat exchanges and by fixing working conditions it is possible to simulate heat transfer according to hourly energy demand: the total energy supply of the system is calculated by the equation (2) related to exhausts at inlet and outlet sections of the tank. Net energy supply is thus obtained by subtracting to this value heat losses, which are estimated through equation (3), that is explicated by equation (6):

$$
\begin{aligned}
& Q_{n}^{\prime}=Q_{o}^{\prime}-Q_{k m}^{\prime} \\
& Q^{\prime}=m_{a}^{\prime} c_{p s} \cdot\left(T_{\text {in }}-T_{\text {as }}\right)
\end{aligned}
$$

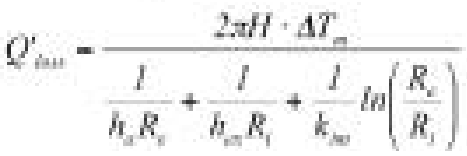

$\mathrm{Q}_{u}$ is regulated by changing exhausts mass flux $\mathrm{m}_{e x}$ which depends on electrical power of the cogenerator. The first step is therefore to fix electrical power in order to obtain a daily net thermal energy supply equal to hourly cumulate energy demand during the day (thermal balance nil) (fig. 3a, 3b). As already said, this latter is fulfilled by heating water that flows into the coil as heat transfer fluid. Its inlet and outlet temperatures are constant in time, and therefore hourly energy supply is regulated by changing its 


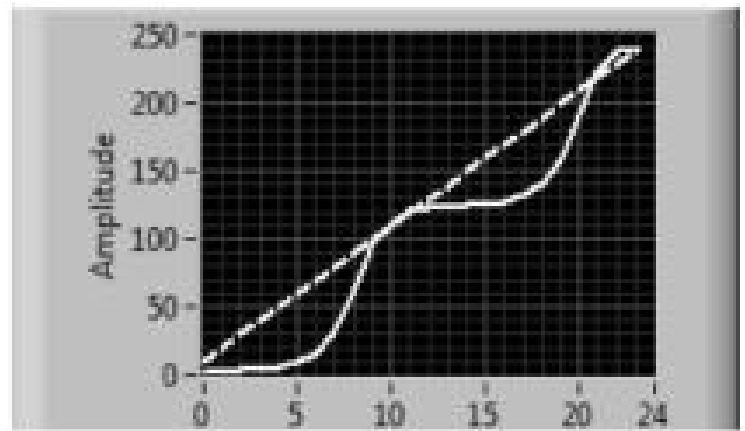

Fig. 3a - daily cumulative trends of heat supply (broken) and demand (continuous) (kWh) (summer season, $18 \mathrm{kWe}$ ).

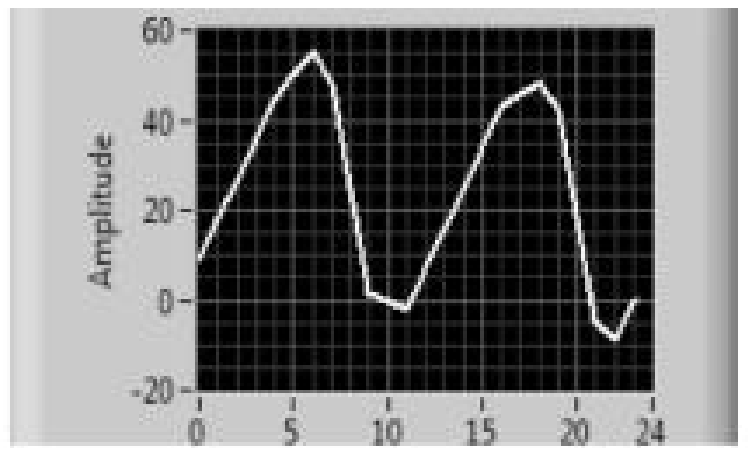

Fig. $3 \mathrm{~b}$ - daily thermal energy balance (kWh) (summer season, 18 $\mathrm{kWe})$.

mass flow $\mathrm{m}_{\mathrm{w}}$, through equation (2) (fig. 4).

Thermal energy is transferred to the heat transfer fluid as the sum of heat exchanges occurring both with spheres and directly with exhausts. These thermal exchanges are considered independent each other:

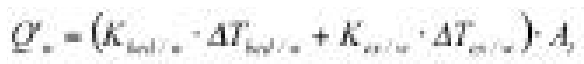

Equation (7) is used to calculate necessary heat exchange surface, $\mathrm{A}_{t}$, that is obtained by putting exchanged thermal power equal to hourly energy demand:

$$
Q^{\prime}=Q_{\text {soo }}^{\prime}
$$

By fixing coil diameter and thickness, it's possible to estimate required coil length as a function of time and its maximum height inside the bed (fig. 5).

Exhausts heat content that is not directly transferred

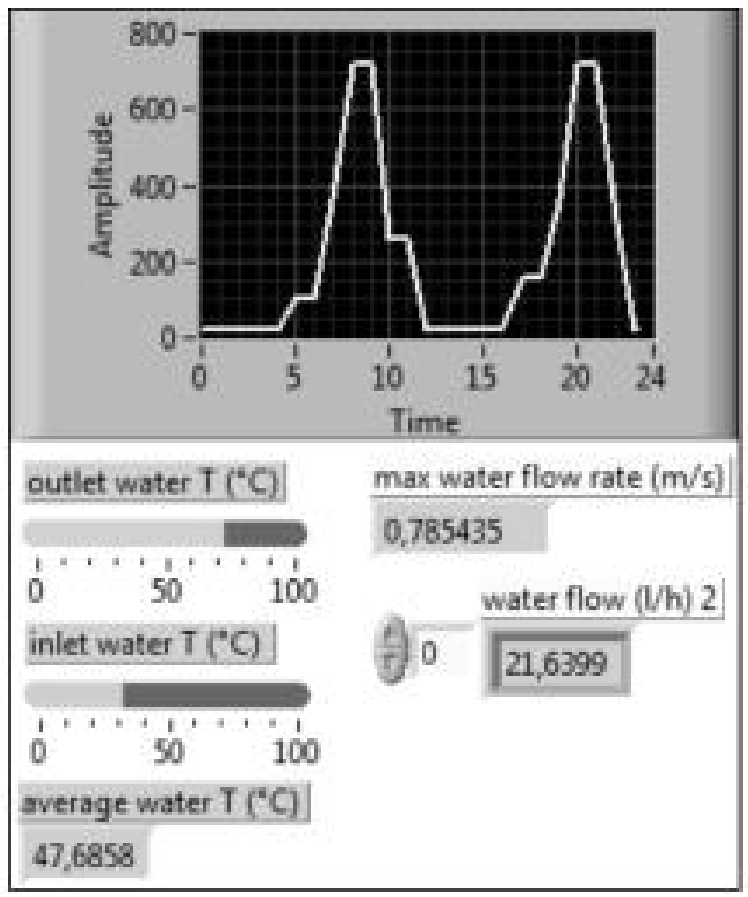

Fig. 4 - Water temperatures, mass flow $(1 / \mathrm{h})$ and maximum flow rate $(\mathrm{m} / \mathrm{s})$.

to water is yielded to the spheres, both in storage phase and in release one. Thermal energy transferred to the PCMs is then calculated by difference between exhausts enthalpy and heat supplied to the coil.

$$
\begin{aligned}
& Q_{s}=Q_{s}-Q_{\omega / \nu} \\
& Q_{e x / \psi}^{\prime}=K_{n / s}-\Delta T_{e x / \psi} \cdot A,
\end{aligned}
$$

The necessary bed surface, $\mathrm{A}_{b e d}$, is then calculated as follows:

$$
Q_{,}=K_{e r \text { ind }} \cdot \Delta T_{e r / \text { ond }} \text { " } A_{\text {hed }}
$$

The model shows $\mathrm{A}_{\text {bed }}$ compared with the real bed surface $S_{b e d}$, in order to verify this latter is always greater than the required surface, according to the dimensions of the tank:

$$
S_{\operatorname{sid}}>A_{\text {ind }}^{\operatorname{mon}}
$$

In order to estimate PCMs amount to be used in

\begin{tabular}{|c|c|c|c|c|c|c|}
\hline $\mathrm{PCM}$ & $\begin{array}{c}\text { latent } \\
\text { heat } \\
(\mathrm{kJ} / \mathrm{kg})\end{array}$ & $\begin{array}{c}\text { melting } \\
\mathrm{T} \\
\left({ }^{\circ} \mathrm{C}\right)\end{array}$ & $\begin{array}{c}\text { density } \\
\text { liquid } \\
\left(\mathrm{kg} / \mathrm{m}^{3}\right)\end{array}$ & $\begin{array}{c}\text { density } \\
\text { solid } \\
\left(\mathrm{kg} / \mathrm{m}^{3}\right)\end{array}$ & $\begin{array}{c}\text { thermal } \\
\text { conductivity } \\
\text { liquid } \\
\left(\mathrm{W} / \mathrm{m}^{* \circ} \mathrm{C}\right)\end{array}$ & $\begin{array}{c}\text { thermal } \\
\text { conductivity } \\
\text { solid } \\
\left(\mathrm{W} / \mathrm{m}^{* \circ} \mathrm{C}\right)\end{array}$ \\
\hline $\mathrm{MgCl}_{2}-6 \mathrm{H}_{2} \mathrm{O}$ & 167 & 117 & 1450 & 1569 & 0,570 & 0,694 \\
\hline Erythritol & 340 & 118 & 1300 & 1480 & 0,326 & 0,733 \\
\hline $68,1 \% \mathrm{KCl}+31,9 \% \mathrm{ZnCl}_{2}$ & 198 & 235 & 2480 & 2480 & $1,1 *$ & 1,1 \\
\hline
\end{tabular}

TABLE 1 - PCM materials characteristics (*: mean value of different chlorates [9]). 


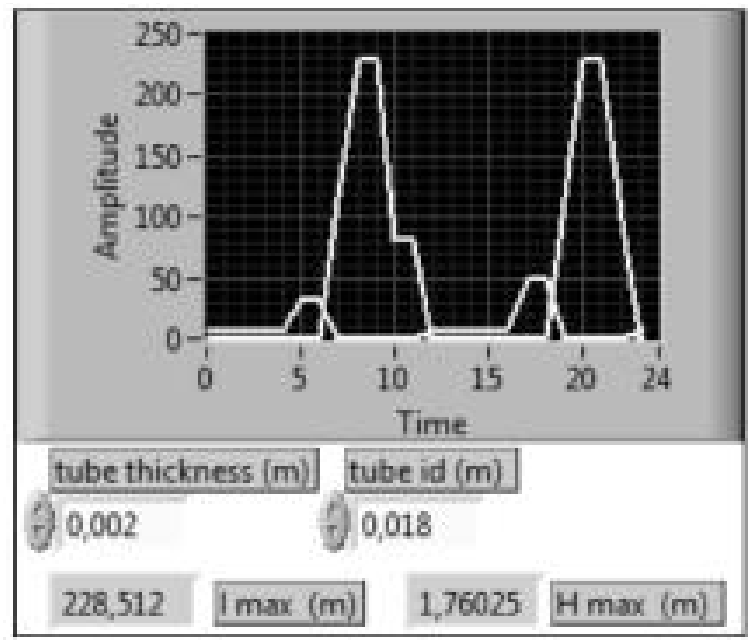

Fig. 5 - Necessary coil length variation as a function of time (m).

solid-liquid phase change, heat storage and release phases are considered separately. These two different working conditions are characterized by different values of net power $\mathrm{Q}_{e f}$, that is calculated as a difference between power transferred from exhausts to the spheres and power exchanged between spheres and heat transfer fluid. (obtained by equation (7))

$$
\begin{aligned}
& Q_{\alpha}=Q_{s}-Q_{\mathrm{h} \alpha / .}
\end{aligned}
$$

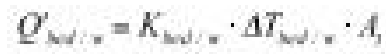

For heat storage phase $\mathrm{Q}_{e f}>0$, while for release phase $\mathrm{Q}_{e f}<0 . \mathrm{Q}_{e f}$ is then cumulated in both of the cases (in absolute value) as a function of time for a day interval, and its values are subsequently divided for latent heat of PCMs. In this way, the first cumulate curve represents materials amount required for daily heat storage $\left(\mathrm{Q}_{e f}>0\right)$, while the other one shows the necessary amount for heat release $\left(\mathrm{Q}_{e f}<0\right)$. By the sum of their maximum values, the whole possible material content used for phase change phenomena is thus obtained (fig. 7). In order to achieve the real phase change variations during the day, hourly cumulate values of $\mathrm{Q}_{e f}$ are summed together, divided for latent heat and added to an half of PCMs amount contained inside the tank (50\% initial percentage). In this way, liquid and solid variations are obtained, as it is shown in figg. 6, 7. Necessary requirement to only consider latent heat exchange is solid/liquid percentages must always be less than $100 \%$. (Otherwise sensible heat exchange should be added and temperatures variations should be considered). Tank dimensions and PCMs content are therefore just dimensioned on the base of this assumption

\section{Results and discussions}

The model was verified by using different system configurations to fulfil thermal energy demand of the same farm (fig. 2). In this way, even useful indications for thermal energy storage unit design were achieved.

Two of geometrical characteristics of the system were changed (tank diameter and spheres diameter) and few different materials types were chosen (table 1).

Constant values, instead, are:

- Inlet temperature of heat transfer fluid: $30^{\circ} \mathrm{C}$

- Outlet temperature of heat transfer fluid: $70^{\circ} \mathrm{C}$

- Inner diameter of pipe coil: $0,018 \mathrm{~m}$

- Thickness of pipe coil: 0,002

- Total height of the tank: $2,5 \mathrm{~m}$

- Thickness of spheres: 0,002 m

- Bed voidage: 0,3

- Thickness of tank insulator: $0,1 \mathrm{~m}$

- Thermal conductivity of tank insulator: $0,035 \mathrm{~W} /$ $\mathrm{m} * \mathrm{~K}$

PCMs amount inside the tank depends both on tank diameter and on spheres diameter (for the different ratio surface/volume), (figg. 8, 9). According to the density values, it can be noticed that $\mathrm{KCl}-\mathrm{ZnCl}_{2}$ mixture shows an higher amount in the tank because of its greater density. As a consequence, the corresponding TES unit weight is also greater and presumably more expensive.

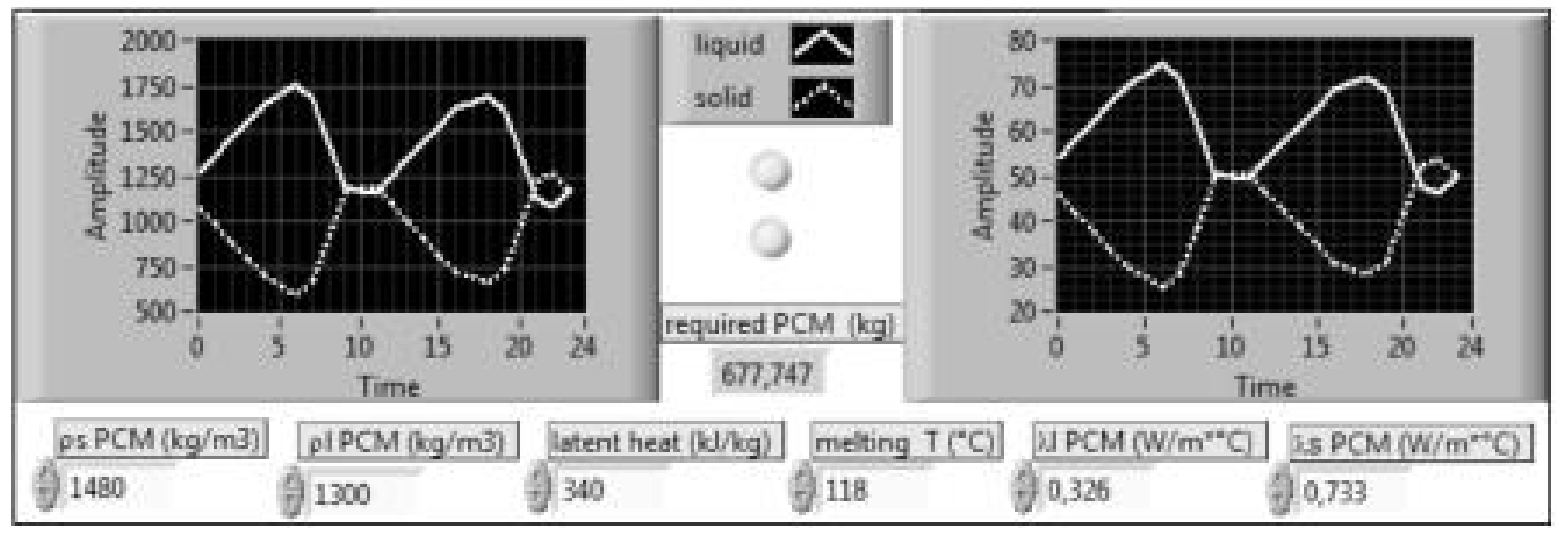

Fig. 6 - Phase change phenomena during the day (Erythritol, summer season). 


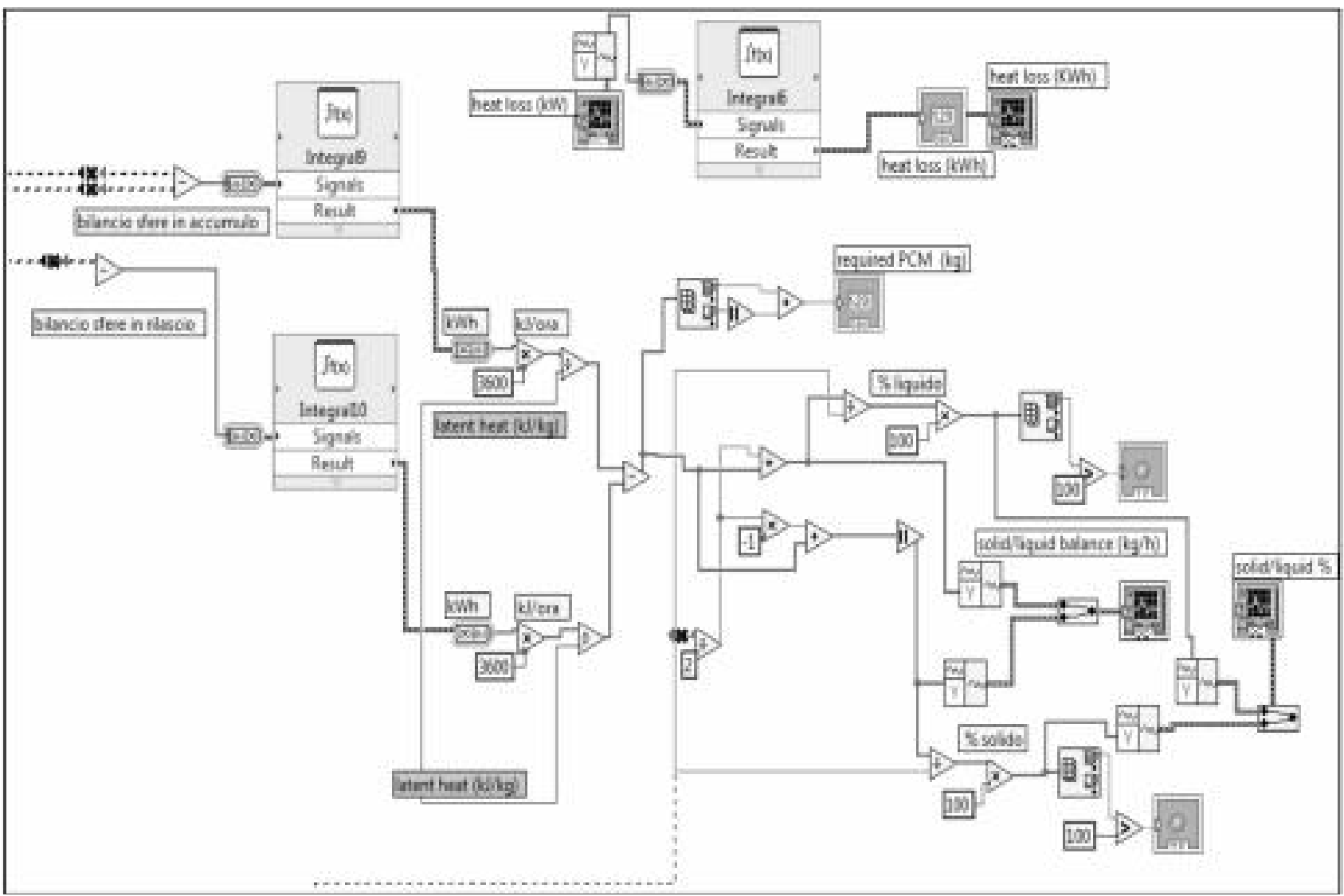

Fig. 7 - PCMs amounts calculations.

According to the model hypothesis, available heat for storage is strictly connected to melting tempera-

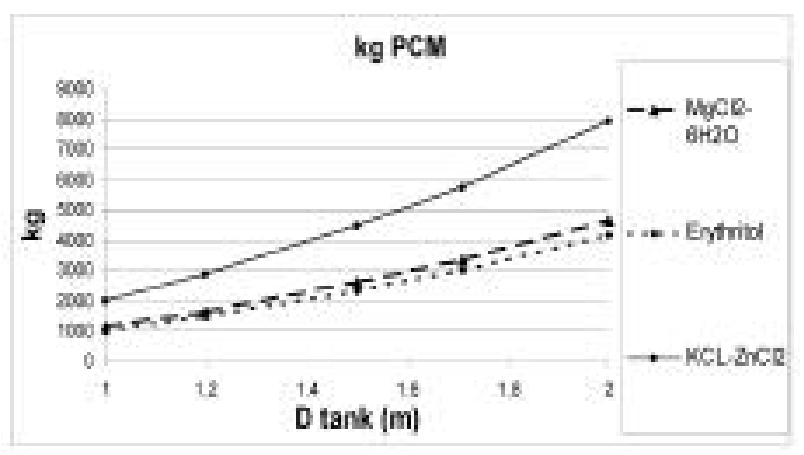

Fig. 8 - Available materials content as a function of tank diameter.

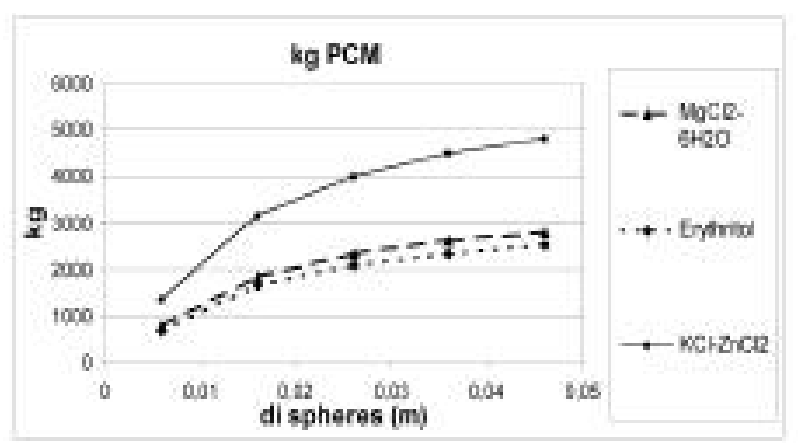

Fig. 9 - Available materials content as a function of spheres diameter. ture of PCMs, since this is related to the outlet exhausts temperature from the tank. Besides, it also depends on tank diameter because of external surface and therefore superficial heat loss.

Necessary electrical load of cogenerator (which thermal load depends on) is thus shown as a function of tank diameter for the three considered PCMs: Erythritol and Magnesium Chlorate have the same melting temperature and therefore the same required electrical load, too (table 1). It is greater, instead, for $\mathrm{KCl}-$ $\mathrm{ZnCl}_{2}$ mixture, that has an higher melting temperature, $\left(235^{\circ} \mathrm{C}\right)$. As a consequence, exhausts enthalpy is used in less quantity (fig. 10).

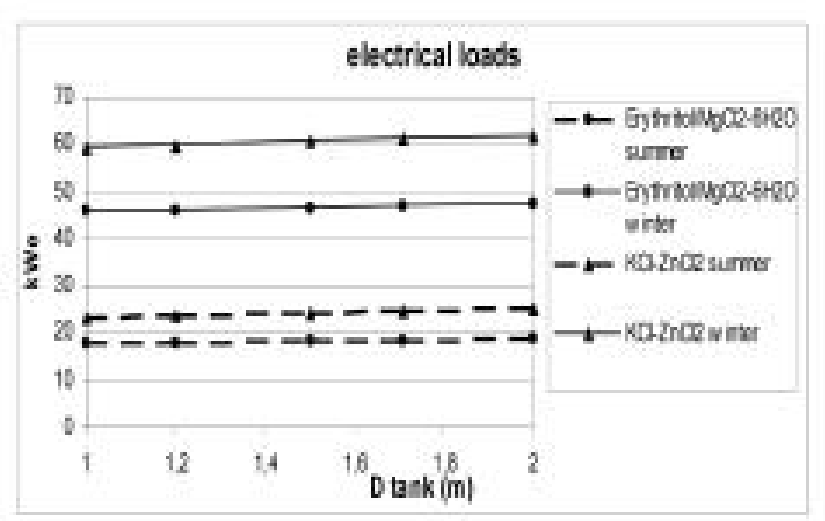

Fig. 10 - Electrical load for different PCMs as a function of tank diameter. 
Spheres diameter has deep influence on thermal exchanges. This is clearly verified by different lengths of pipe coil (exchange surface) in dependence on capsules diameter values. As an example, results regarding Erythritol storage unit (winter season, tank diameter $=1,5 \mathrm{~m}$ ) with $0,016 \mathrm{~m}$ and $0,046 \mathrm{~m}$ spheres diameter are shown (fig. 11a, 11b).

Differences among the PCM materials types are presented as regard to the maximum necessary length of the coil (fig. 12).

One of the main function of the model is to estimate the right dimensions of the tank and of the spheres according to thermal energy demand. As already said, for each unit configuration, hourly solid/liquid percentage variations are shown.

By considering maximum values of these percentages it is possible to estimate the minimum dimen-

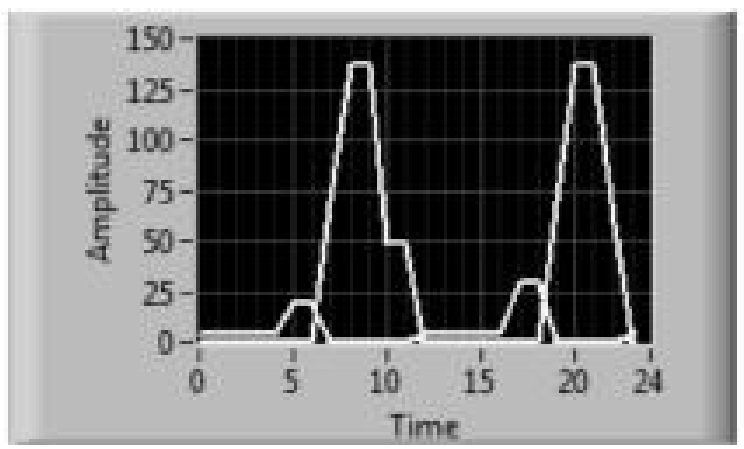

Fig. 11a - Pipe coil length for heat exchange with $0,016 \mathrm{~m}$ diameter spheres (m).

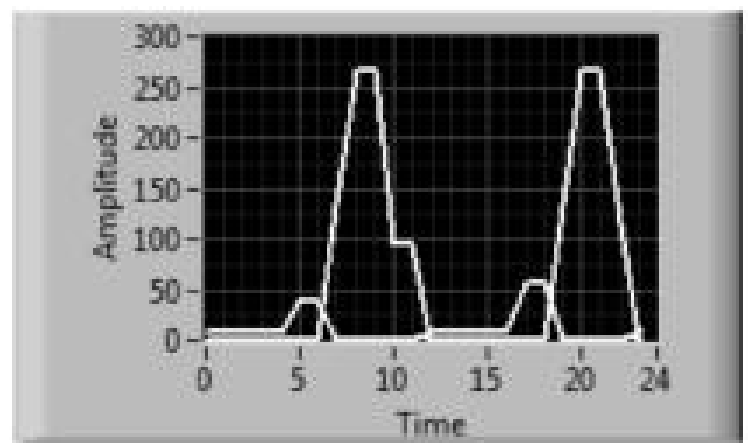

Fig. 11b - Pipe coil length for heat exchange with $0,046 \mathrm{~m}$ diameter spheres.

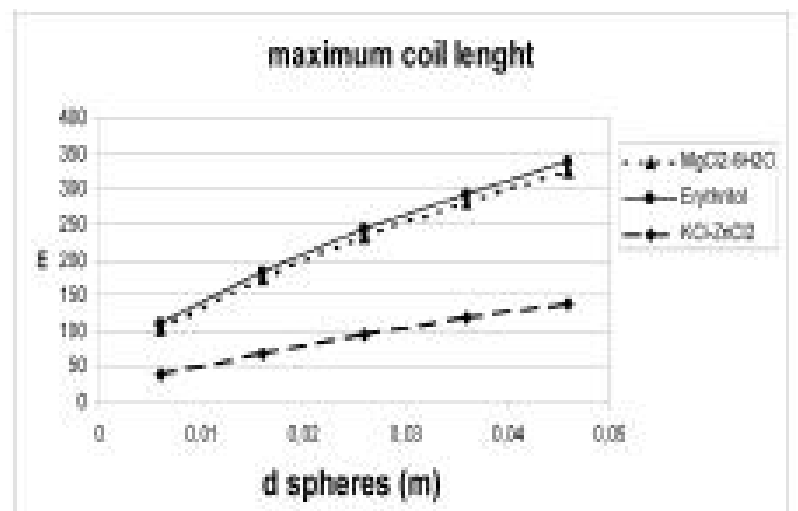

Fig. 12 - Maximum pipe coil length as a function of spheres diameter. sions permitting to remain under $100 \%$. In this way, for each material, it is possible to know the necessary dimensions of the heat storage unit, and, as a consequence, their amount and presumably their costs.

Curves corresponding to summer and winter seasons are very similar because their difference is due to room heating and food preparing only, which are constant operations during the day. Therefore they don't have influence on melting and solidification cycles, even if winter season obviously shows an higher heat demand.

Higher percentages for liquid phases are also due to the specific trend of energy load curves: they show two energy peaks at about 8:00 and 21:00, while their values are less than thermal supply during almost all the other hours of the day. Since model simulation start at 24:00, during the first hours of the day melting phase occurs with the increase of liquid percentage. During the hours of energy demand peaks, part of the same melted material hardens, decreasing liquid percentage to about initial value. Therefore, very high solid percentages never occur during the day.

For dimensioning, in this mentioned case, it is necessary to use tank diameters greater than $1 \mathrm{~m}$ for each kind of material, (spheres diameter $=0,036 \mathrm{~m}$ ), and even greater than $1,5 \mathrm{~m}$ for $\mathrm{MgCl}_{2}-6 \mathrm{H}_{2} \mathrm{O}$. This is due to different values of latent heat, the influence of which is also registered in dimensioning capsules diameter.

Indeed, for Erythritol and $\mathrm{KCl}-\mathrm{ZnCl}_{2}$, spheres diameters greater than $0,015 \mathrm{~m}$ are required, while for $\mathrm{MgCl}_{2}-6 \mathrm{H}_{2} \mathrm{O}$ a $0,035 \mathrm{~m}$ diameter is necessary (tank diameter $=1,5 \mathrm{~m}$ ).

Different sets of selected geometrical parameters could obviously show different results.
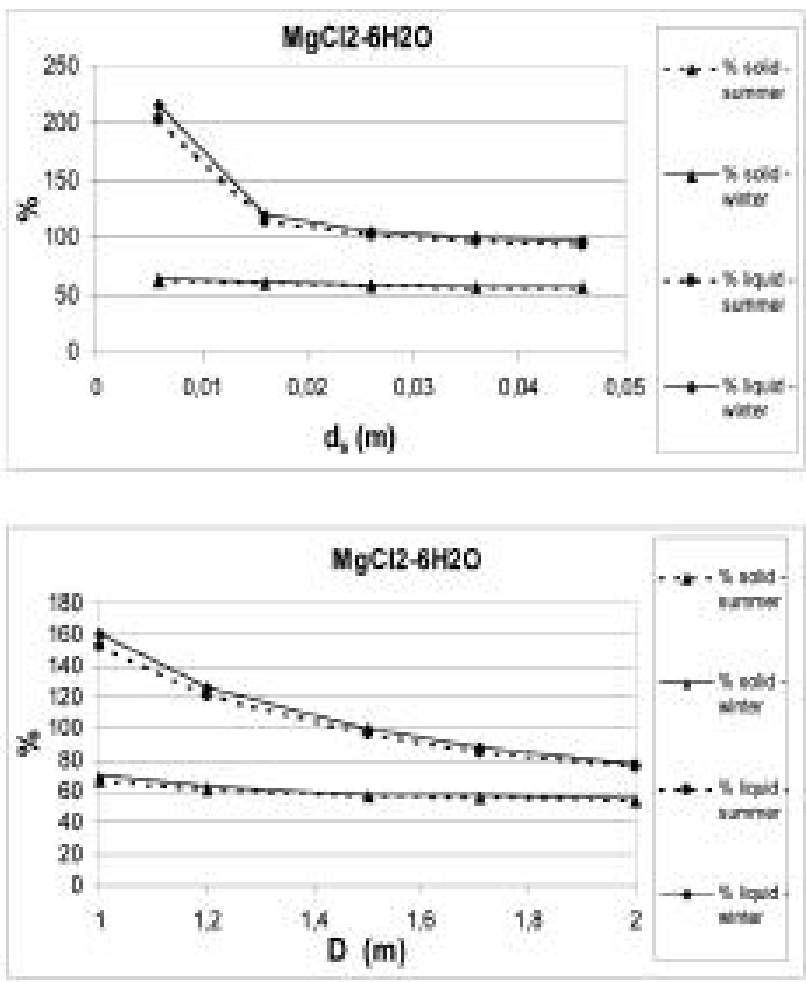

Fig. 13 - Maximum percentages of $\mathrm{MgCl}_{2}-6 \mathrm{H}_{2} \mathrm{O}$ to be used, as a function of spheres and tank diameter. 


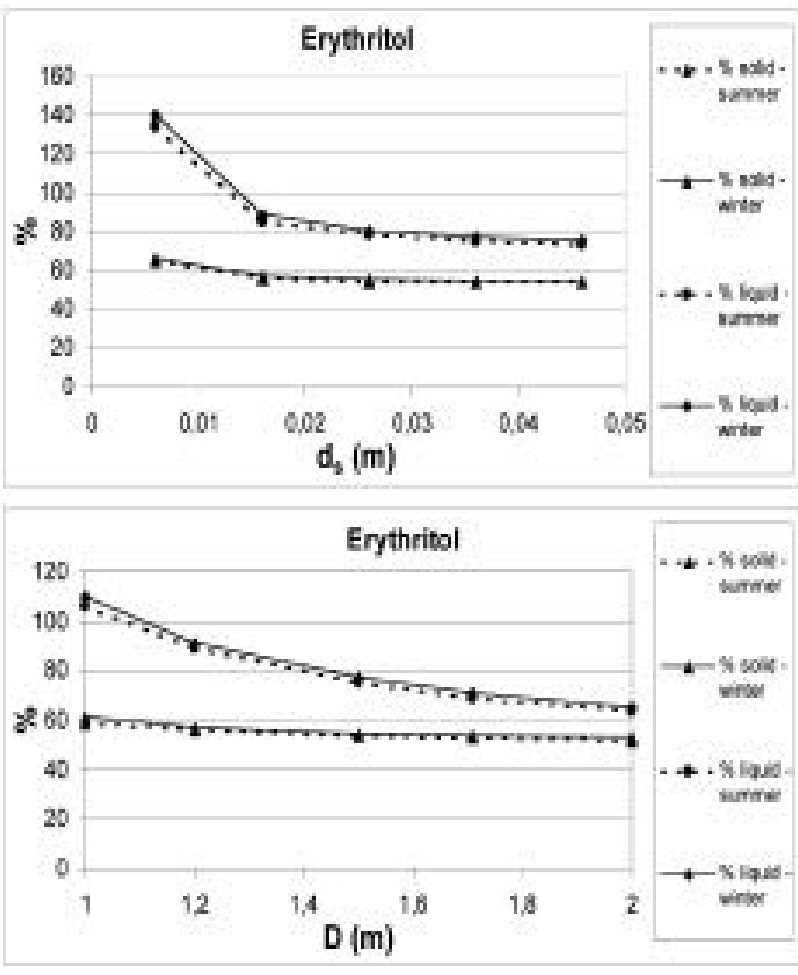

Fig. 14 - Maximum percentages of Erythritol to be used, as a function of spheres and tank diameter.

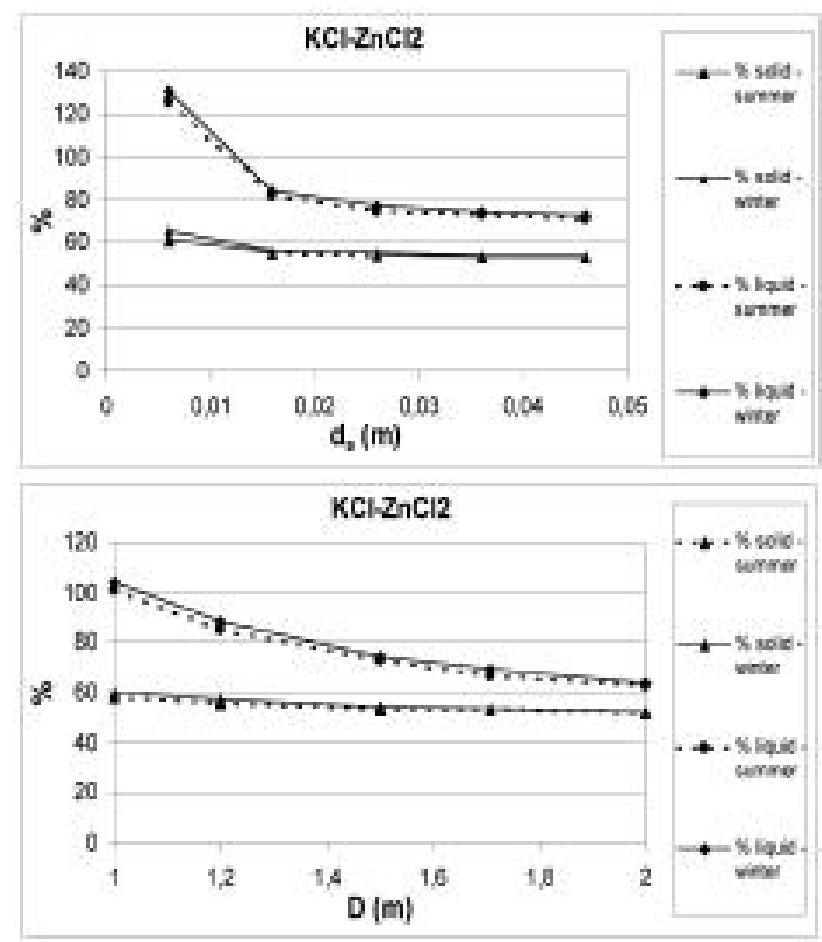

Fig. 15 - Maximum percentages of $\mathrm{KCl}-\mathrm{ZnCl}_{2}$ to be used, as a function of spheres and tank diameter.

\section{Conclusions}

Thermo-physical behaviour of a heat storage unit was investigated by means of a numerical simulation model that has been developed with the main aim at ascertaining technical and economic feasibility of us- ing phase change materials (PCMs) as thermal energy storing materials in several applications (by checking reduced dimensions of the necessary equipment in respect with other heat storage systems). At this scope heat storage unit was thought to be designed as a fixed (or even fluidized) bed of spherical capsules in which PCMs are filled. In the examined case, spheres are then licked by combustion exhausts from a reciprocating engine that is used as cogeneration unit. The only use of exhausts as thermal energy source allows to have heat exchanges at higher mean temperatures (about $250^{\circ} \mathrm{C}$ ) and thus to use PCMs with higher melting temperatures, as well. Nevertheless the overall thermal energy supply is decreased.

Encapsulation of PCMs in spherical capsules increase heat exchange surface between exhausts and storing materials as to face with their low thermal conductivity. Besides, this technique avoids environmental hazards due to chemical aggressiveness of PCMs towards tank walls. Another main characteristic of this thermal energy storage unit is the geometrical shape of heat exchanger in which heat transfer fluid flows, by which it is possible to follow daily heat demand by regulating its exchange surface.

Preliminary analytical model (developed by LabView 8.0 software) is only based on energy and mass balance and steady state heat exchange equations. It permits to investigate different working conditions, since geometrical characteristics of the storage unit and types of materials are inserted as input data, while necessary energy supply and hourly phase changes of materials are shown as results. Energy supply is deeply influenced by melting temperature of the materials, as it defines outlet exhausts temperature from the tank and hence exhausts enthalpy used for storing. Materials amounts are instead estimated by means of their own latent heat, according to thermal energy demand.

As an example, a real case of a cattle farm (100 cattle heads) was considered. Its electrical and thermal energy load curves are characterized by two main daily peaks corresponding to the milking operations. They were inserted into the model and three kinds of PCMs were investigated. Tank, capsules and coil diameters were chosen as geometrical variables, the values of which resulted acceptable for each PCM. Therefore, by this first results it seems PCMs are a suitable solution especially for applications in which thermal energy demand shows great variability, for which a lot of stored heat is required. Further developments of the model will be carried out to verify this assumption and to apply it in other several applications, particularly in those where not only heat demand but also energy supply are not constant in time (for example, solar energy collectors in domestic and agro-industrial context).

\section{References}

[1] Mazza S., VACCA G., Le zeoliti come accumulatori di energia termica nell'industria agro-alimentare, atti 
del V Convegno nazionale AIGR, 7-11/06/1993 "Il ruolo dell'ingegneria per l'agricoltura del 2000", vol. 5, 99-103.

[2] KÜRKLÜ A., Energy storage applications in greenhouses by means of phase change materials (PCMs): a review, Renewable Energy, Vol. 13, No. 1, 1998, 89-103.

[3] Maidment G., Missenden J., Tozer R., Wang F., The novel use of phase change materials in refrigeration plant. Part 2: Dynamic simulation model for the combined system, Applied thermal Engineering, 2005.

[4] Al-Hallaj S., Farid M.M., Khudhair A.M., RazaCK K.S. ALì, A review on phase change energy storage: materials, applications, Energy Conversion and Management, 2004, 45, 1597-1615.

[5] EPA, Combined Heat and Power Partnership, Catalogue of Heat and Power Technologies, 2002, 14-15

[6] Castelli G., Pellizzi G., Agricoltura, Energia e Sistemi Integrati, Franco Muzzio \& Co. Editore, 1984, 17-26.

[7] Balsari P., Bodria L., Castelli G., Guidobono Cavalchini A., Natalicchio E., Pellizzi G., Pieretti G., RIVA G., SANGIORGI F., Sistemi energetici integrati in agricoltura: tre esempi di studio di realtà diverse, CNR - progetto finalizzato meccanizzazione agricola, Quaderno 22, 1981.

[8] Cabeza L.F., Marin J., Mehling H., Zalba B., Review on thermal energy storage with phase change: materials, heat transfer analysis and applications.

[9] BitTar A., Hoshi A., Mills D.R., SAITOH T.S., Screening of high melting point phase change materials (PCM) in solar thermal concentrating technology based on CLFR, Solar Energy, 2005, 79, 332-339.

[10] AA.Vv., Manuale dell'Ingegnere, Nuovo Colombo, Hoepli, 84 ed., vol. I, B93-B102.

[11] KunII D., LeVensPiel O., Fluidization Engineering, Butterworth-Heinemann, II ed., 324-326.

\section{SUMMARY}

The continuous increase in the mechanization of farm activities, the rise in fuel prices and the environmental aspects concerning gas emissions are the main driving forces behind efforts toward more effective use of renewable energy sources and cogeneration systems even in agricultural and cattle farms. Nevertheless these systems are still not very suitable for this purpose because of their little flexibility in following the changing energy demand as opposed to the extremely various farm load curves, both in daytime and during the year. In heat recovery systems, the available thermal energy supply is always linked to power production, thus it does not usually coincide in time with the heat demand. Hence some form of thermal energy storage (TES) is necessary in order to reach the most effective utilization of the energy source.

This study deals with the modelling of a packed bed latent heat TES unit, integrating a cogeneration system made up of a reciprocating engine.

The TES unit contains phase change materials (PCMs) filled in spherical capsules, which are packed in an insulated cylindrical storage tank. Water is used as heat transfer fluid (HTF) to transfer heat from the tank to the final uses, and exhausts from the engine are used as thermal source.

PCMs are considered especially for their large heat storage capacity and their isothermal behaviour during the phase change processes. Despite their high energy storage density, most of them have an unacceptably low thermal conductivity, hence PCMs encapsulation technique is adopted in order to improve heat transfer.

The special modular configuration of heat exchange tubes and the possibility of changing water flow through them allow to obtain the right amount of thermal energy from the tank, according to the hourly demand of the day.

The model permits to choose the electrical load of the engine, the dimensions of the tank and the spheres, thickness and diameter of heat exchanger and the nature of PCMs.

According to the energy loads of the farm, a daily thermal energy balance is obtained and charging and discharging cycles during the day are showed as sol$\mathrm{id} /$ liquid percentages of the PCM.

As an example, load curves of a milk cattle farm (100 heads of cattle), were considered in two different conditions, such as in summer and winter seasons, and model functioning was detected in both of the cases. Different PCMs were investigated for this application and TES unit dimensions were consequently changed in order to achieve optimal operating conditions. Results are presented and technical and economical issues are discussed.

\section{Key words:}

cogeneration, heat recovery, thermal load curves, PCM, latent heat storage.

\section{Notation:}

PCMs: Phase change materials

$\mathrm{T}$ : temperature $\left[\mathrm{K},{ }^{\circ} \mathrm{C}\right]$

$\mathrm{Q}$ : thermal energy $[\mathrm{kJ}]$

Q': heat flow $[\mathrm{kW}]$

m: mass $[\mathrm{kg}]$

$\mathrm{m}$ : mass flow $[\mathrm{kg} / \mathrm{h}]$

$\Delta \mathrm{T}$ : difference of temperature $\left[\mathrm{K},{ }^{\circ} \mathrm{C}\right]$

$\Delta \mathrm{T}_{m(i / j)}$ : logarithmic average difference of temperature between heat transfer fluids $\left[\mathrm{K},{ }^{\circ} \mathrm{C}\right],[10]$

$\mathrm{K}_{(i / j)}$ : global heat transfer coefficient $\left[\mathrm{W} / \mathrm{m}^{2} \cdot \mathrm{K}\right]$

A: heat transfer surface $\left[\mathrm{m}^{2}\right]$

$\mathrm{H}$ : total height of the tank [m]

$\mathrm{R}$ : tank radius [m]

D: tank diameter [m]

$\mathrm{d}_{\mathrm{s}}:$ spheres diameter $[\mathrm{m}]$

$\mathrm{r}_{s}$ : spheres radius $[\mathrm{m}]$

$\mathrm{s}_{s}$ : spheres thickness [m]

$\mathrm{d}_{t}$ : tubes diameter $[\mathrm{m}]$

$\mathrm{r}_{t}$ : tubes radius $[\mathrm{m}]$ 
$\mathrm{s}_{t}$ : tubes thickness [m]

$\mathrm{D}_{s p}:$ spiral diameter $[\mathrm{m}]$

$\mathrm{S}_{\text {bed }}$ : bed surface, $\mathrm{S}_{\text {bed }}{ }^{*} \mathrm{~V}_{\text {bed }}\left[\mathrm{m}^{2}\right]$

$\mathrm{S}^{\prime}{ }_{\text {bed }}$ : specific bed surface, $(1-\varepsilon) \cdot 6 / \mathrm{d}_{\text {se }}\left[\mathrm{m}^{2} / \mathrm{m}^{3}\right][11]$

$\mathrm{V}_{\text {bed }}$ : bed volume $\left[\mathrm{m}^{3}\right]$

W: volumetric exhausts flow $\left[\mathrm{m}^{3} / \mathrm{s}\right]$

$\mathrm{v}$ : velocity $[\mathrm{m} / \mathrm{s}]$

$\mathrm{u}$ : superficial velocity $4 \cdot \mathrm{W} / \pi \cdot \mathrm{D}_{\mathrm{i}}^{2}[\mathrm{~m} / \mathrm{s}]$

$\mathrm{c}_{\mathrm{p}}$ : specific heat $[\mathrm{kJ} / \mathrm{kg} \cdot \mathrm{K}]$

$\mathrm{k}$ : thermal conductivity $[\mathrm{W} / \mathrm{m} \cdot \mathrm{K}]$

$\mathrm{h}$ : convective heat transfer coefficient $\left[\mathrm{W} / \mathrm{m}^{2} \cdot \mathrm{K}\right]$

$\mathrm{Nu}$ : Nusselt number, h.D/k

Pr: Prandtl number, $\mu \cdot c_{\mathrm{p}} / \mathrm{k}$

Gr: Grashof number, $9,81 \cdot \rho^{2} \cdot \mathrm{D}^{3} \cdot \beta \cdot \Delta \mathrm{T}_{m} / \mu^{2}$

$\mathrm{Q}^{\prime}{ }_{\mathrm{w}}$ : heat flow transferred to heat transfer fluid $[\mathrm{kW}]$

$\mathrm{Q}_{\mathrm{s}}$ : heat flow transferred to spheres $[\mathrm{kW}]$

$\mathrm{Q}_{\text {dem }}$ : thermal energy demand $[\mathrm{kW}]$

$\mathrm{Nu}_{w}$ : water Nusselt number, $0,0023 \cdot \operatorname{Pr}_{w}{ }^{0,4} \cdot \operatorname{Re}_{w}{ }^{0,8}$

$\operatorname{Re}_{w}$ : water Reynolds number, $\rho_{w} \cdot \mathrm{d}_{t i} \cdot \mathrm{v}_{w} / \mu_{w}$

$\mathrm{h}^{0}{ }_{w}^{w}$ : convective heat transfer coefficient for water in straight tubes, $\mathrm{Nu}_{w} \cdot \mathrm{k}_{w} / \mathrm{d}_{t i}\left[\mathrm{~W} / \mathrm{m}^{2} \cdot \mathrm{K}\right]$

$\mathrm{h}_{w}$ : convective heat transfer coefficient for water in circular tubes, $\mathrm{h}_{w}^{0} \cdot\left(1+3,5 \mathrm{~d}_{t i} / \mathrm{D}_{s p}\right)\left[\mathrm{W} / \mathrm{m}^{2} * \mathrm{~K}\right]$

$\mathrm{Nu}_{a}$ : air Nusselt number, 0,17. $\left(\mathrm{Gr}_{a} * \operatorname{Pr}_{a}\right)^{1 / 3}$

$\mathrm{Nu}_{e x}$ : exhausts Nusselt number, $2+1,8 \cdot \operatorname{Pr}_{e x}{ }^{1 / 3} \cdot \operatorname{Re}_{e x}{ }^{1 / 2}$

$\mathrm{Re}_{e x}$ : exhausts Reynolds number, $\rho_{e x} \cdot \mathrm{d}_{s e} \cdot \mathrm{u}_{e x} / \mu_{e x}$

$\mathrm{K}_{b e d / w}$ : global heat transfer coefficient between spheres and water,

$1 /\left(1 / h_{w}+\left(r_{t m} / k_{s}\right) \cdot \ln \left(r_{t e} / r_{t i}\right)+1 / h_{b e d / t}+s_{s} / k_{s}+r_{s i} / k_{l p c m}\right)$ $\left[\mathrm{W} / \mathrm{m}^{2} \cdot \mathrm{K}\right] \mathrm{h}_{\text {bed/t }}$ : heat transfer coefficient between bed of spheres and tubes surface,

$2 k_{b e d} / d_{s e}+\alpha \cdot \cdot\left(c_{p e x} \rho_{e x} u_{e x}\right)\left[\mathrm{W} / \mathrm{m}^{2} \cdot \mathrm{K}\right] \quad$ [11]

$\mathrm{k}_{b e d}$ : conductive heat transfer coefficient for the bed of spheres,

$\varepsilon \cdot k_{e x}+(1-\varepsilon) \cdot k_{s}\left[1 /\left(k_{s} / k_{e x}+1 / 3\right)\right][\mathrm{W} / \mathrm{m} \cdot \mathrm{K}]$

$\mathrm{K}_{e x / w}$ : global heat transfer coefficient between exhausts and water,
$1 /\left(1 / h_{w}+\left(r_{t m} / k_{s}\right) \cdot \ln \left(r_{t e} / r_{t i}\right)+1 / h_{e x}\right)$

$\mathrm{K}_{\text {ex/bed }}$ : global heat transfer coefficient between exhausts and spheres,

$1 /\left(r_{s i} / k_{s p c m}+s_{s} / k_{s}+1 / h_{e x}\right)$

Subscripts:

$a$ : air

bed: bed of spheres

dem: energy demand

$e$ : external

ef: effective

ex: exhausts

$i$ : internal

in: inlet section of the tank

$i m$ : insulation material

loss: heat loss

lpcm: PCM in liquid phase

spcm: PCM in solid phase

$m$ : logarithmic average

out: outlet section of the tank

$s$ : spheres

$s p$ : spiral

$t$ : tubes

$u$ : usable

$w$ : water (heat transfer fluid)

bed/t: bed of spheres/tubes

bed/w: bed of spheres/water

$e x / w$ : exhausts/water

$e x / t$ : exhausts/tubes

ex/bed: exhausts/bed of spheres

\section{Greek symbols:}

$\alpha$ : empirical value, 0,05

$\beta$ : thermal dilatation coefficient, $1 / \mathrm{T}\left[\mathrm{K}^{-1}\right]$

$\varepsilon$ : bed voidage

$\lambda$ : latent heat $[\mathrm{kJ} / \mathrm{kg}]$

$\mu$ : dynamic viscosity $\left[\mathrm{N}^{*} \mathrm{~s} / \mathrm{m}^{2}\right]$

$\rho$ : density $\left[\mathrm{kg} / \mathrm{m}^{3}\right]$ 